\title{
A Monitoring Network on Acidification in Flanders, Belgium
}

\author{
Bo Van den Bril, Dominique Meremans, and Edward Roekens \\ Vlaamse Milieumaatschappij (VMM), Afdeling Lucht, Milieu en Communicatie, \\ Kronenburgstraat 45 Bus 3, 2000 Antwerpen, Belgium
}

Received 18 August 2011; Accepted 3 October 2011

Academic Editor: Richard Brown

This paper presents the monitoring of acid deposition in Flanders (Belgium) and the change of the measurement objectives, recently towards measurement of ammonia. The monitoring network on acidification has provided results for 10 years. Analysis of acidifying pollutants between 2005 and 2010 shows decreasing concentrations throughout the whole period. $\mathrm{NO}_{2}$ has no significant trend, although the average total deposition in $2010(2027 \mathrm{Eq} / \mathrm{ha}$.y) is still higher than the objectives of the Flemish environmental policy plan for 2015 (1800 Eq/ha.y). Given the contribution of ammonia, the Flemish Environmental Agency has the aim to develop a policy-oriented monitoring network on ammonia. Studies on this subject have already been extensively conducted.

KEYWORDS: measuring methods, acid deposition, ammonia, mathematical modelling, sampling strategy 


\section{A MONITORING NETWORK ON ACIDIFICATION IN FLANDERS, BELGIUM}

As a member of the European Union, Belgium has obligations and responsibilities to conform to European air quality directives. Environment is a regional matter in Belgium. The Flemish Environment Agency, hereinafter referred to as VMM (Vlaamse Milieumaatschappij), is responsible for the Flanders region of the country (see Figure 1). The EU ratified a directive in 2001 (2001, 2001/81/EG), a National Emission Ceiling Directive or NEC Directive. This directive was set internationally to determine cross-border environmental problems. Beside this, the European Community ratified the Göteborg protocol. This is the 8th Protocol of the EU Directive (2008/50/EG), part of the Long-Range Transboundary Air Pollution (LRTAP) [1]. To meet the obligations for reporting, VMM makes an inventory of the emissions of $\mathrm{SO}_{2}, \mathrm{NO}_{x}$, and $\mathrm{NH}_{3}$ and compares it with the emission ceilings. From the emission ceilings for $\mathrm{SO}_{2}, \mathrm{NO}_{x}$, and $\mathrm{NH}_{3}$, guide values for the deposition are calculated by the VLOPS model (see further) and compared with modelled deposition based on actual emission values. Additional, VMM reports results of measurements of pesticides, acidification, heavy metals, and mercury in air and deposition under a project called OSPARCAMP (the Comprehensive Atmospheric Monitoring Programme (CAMP) aims to assess the input of selected contaminants to the OSPAR maritime area and its regions via atmospheric deposition).

Although the emission of most pollutants decreased during the last decades, the concentration or deposition of some pollutants remains to high [2]. The pollutants emitted can cause adverse health effects and have the potential to cause environmental damage [3]. Air pollutants may be natural or man made and may take the form of solid particles, liquid droplets, or gases. These pollutants are divided into various groups, including particulate matter $\left(\mathrm{PM}_{2.5}\right.$ and $\mathrm{PM}_{10}$ - particles with an aerodynamic diameter of 2.5 and 10 microns or less, resp.), heavy metals and also potential acidifying components.

Air pollution is a complex matter, comprising it almost invariably does a mixture of many different substances, some of which are more toxic than others [4]. Most of these pollutants are measured in Flanders by the VMM by either automated or semiautomated methods. Figure 2 gives an overview of the different monitoring locations in Flanders.

The monitoring network for acidification measurement, pertaining to the semiautomatic measurements, has now provided results for 10 years in Flanders and is tending more and more towards ammonia measurements.

Processes associated with "acid rain" were identified in the 1960s. Acid deposition, better known as acid rain can be defined as the deposition of sulphur, nitrogen, and ammonia. Acidification, the major removal pathway for secondary pollutants, can occur as wet deposition (in precipitation such as rain, snow and hail), dry deposition (gaseous or aerosol particles), or occult deposition (fog, dew, smoke, and smog). The sum of dry and wet deposition is defined as the total acid deposition [5-7]. On the other hand, equivalent $(\mathrm{Eq})$ is then the unit to measure the level of acidification of pollutants. It permits to compare different acidifying components with each other. One Eq corresponds with $32 \mathrm{~g} \mathrm{SO}_{2}, 46 \mathrm{~g} \mathrm{NO}_{x}$, or $17 \mathrm{~g}$ $\mathrm{NH}_{3}$. The monitoring network for acid deposition in Flanders comprises nine measuring points for wet and dry potential acid deposition and also ten additional measuring points for ammonia.

Precipitation is collected by placing automatic wet-only samplers (Eigenbrodt) in the open field with an orifice diameter of $25.4 \mathrm{~cm}$ and activated by resistance-driven or optical sensors (RS 85 and IRSS 88, Eigenbrodt). The use of wet-only samplers, in which the funnel is open to the atmosphere only during precipitation events, is widely practiced in Europe. Precipitation is collected in bottles for two weeks. The amount of precipitation was measured by tipping bucket collectors (C101 A, Lastem) with a $16 \mathrm{~cm}$ orifice diameter until 2008. Since 2009, precipitation amounts have been determined with weighing gauges (Pluvio ${ }^{2}$ 200, Ott). The samples are then transferred to the lab and analysed by ion chromatography (Dionex ICS1000) for its chemical composition of a number of ions $\left(\mathrm{NH}_{4}{ }^{+}, \mathrm{Na}^{+}, \mathrm{K}^{+}, \mathrm{Ca}^{2+}, \mathrm{Mg}^{2+}, \mathrm{F}^{-}, \mathrm{Cl}^{-}, \mathrm{NO}_{2}{ }^{-}, \mathrm{NO}_{3}, \mathrm{SO}_{4}{ }^{2-}, \mathrm{HCO}_{3}{ }^{-}\right.$, and $\left.\mathrm{PO}_{4}{ }^{3-}\right)$. The total wet deposition is then given as the amount of precipitation multiplied by the concentration of the pollutant [8].

On the other hand, dry deposition of $\mathrm{NH}_{3}, \mathrm{SO}_{2}$, and $\mathrm{NO}_{2}$ is estimated by multiplying the air concentrations derived from passive diffusion sampler measurements by a literature-based values for the 


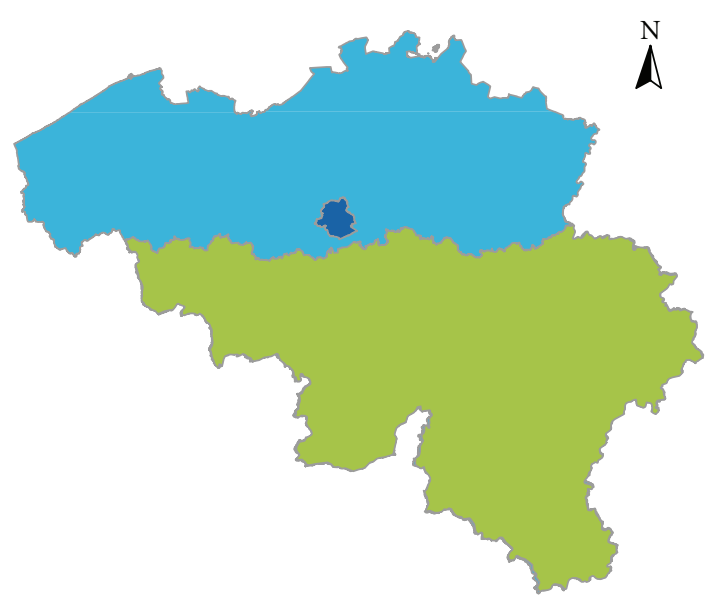

FIGURE 1: Map of Belgium, with in the north the Flemish part, in the south the French part, and Brussels as the dark blue region close to the border of het two other regions.

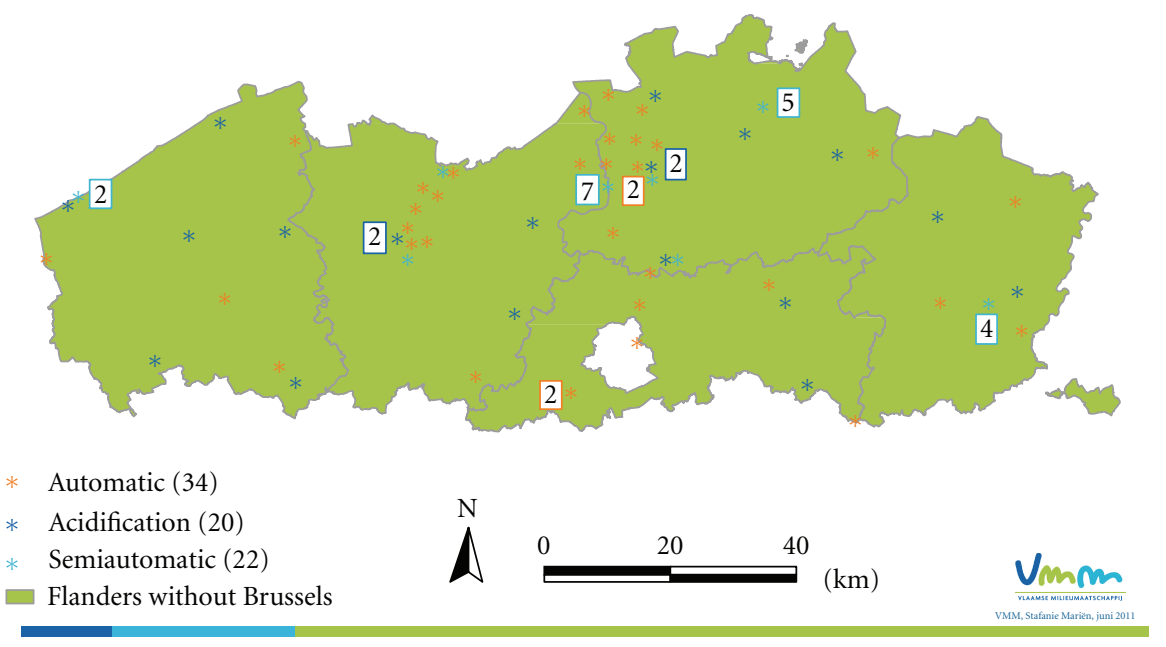

FIGURE 2: Map of Flanders, with the spread of monitoring stations for automatic and semiautomatic measurements.

dry deposition velocity $\left(v_{d}\right)$. The value of $v_{d}$ depends, amongst other factors, on the gas considered, meteorological conditions, surface roughness, and stomatal characteristics and thus varies over time and with vegetation type [9]. Air concentrations are measured with the passive sampling technique, using Radiëllo (Italy) and IVL (Sweden) samplers, to adsorb atmospheric $\mathrm{NH}_{3}, \mathrm{SO}_{2}$, and $\mathrm{NO}_{2}[10,11]$. Therefore a shelter (for protection from precipitation) is placed at a height of $3 \mathrm{~m}$ and in which the samplers are hung in triplicate. Every two weeks the samplers are collected, transferred to the lab, and then analysed for $\mathrm{NH}_{3}, \mathrm{SO}_{2}$, and $\mathrm{NO}_{2}$ by ion chromatography (Dionex ICS1000). Figure 3 shows average concentrations of acidifying pollutants between 2005 and 2010 across the Flanders region. For $\mathrm{NH}_{3}$ there is a gradual decrease in concentration due to a new agriculture policy (low-emission housing, processing manure, nutritional value, etc.) [12]. For $\mathrm{SO}_{2}$ there is a strong decrease from 2006. This is a result of both the use of cleaner energy and decrease by households. For $\mathrm{NO}_{2}$ the mean values are stable. There are not any concluding remarks about these small differences. All the other pollutants have decreasing concentrations throughout the whole period.

Eventually the total deposition is calculated for the deposition on different vegetation types: coniferous forest, broad-leaved forest, heath, and grassland and a trend analysis is performed (see Figure 4). 


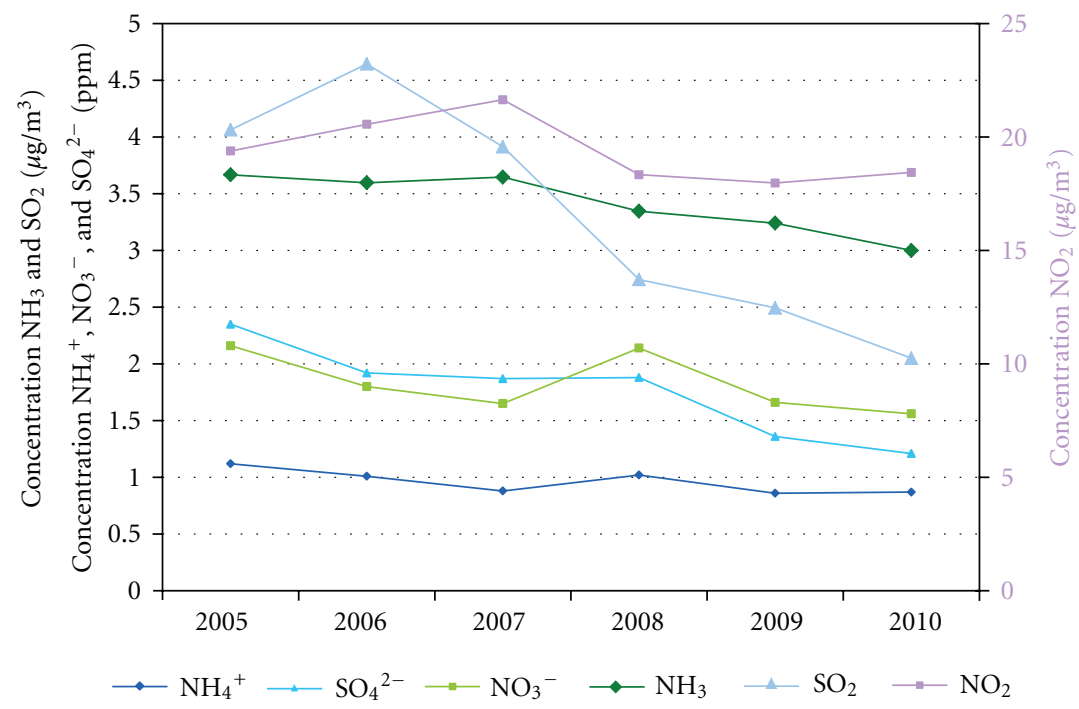

FIGURE 3: Average concentrations of acidifying pollutants between 2005 and 2010 across Flanders. $\mathrm{NH}_{3}$ and $\mathrm{SO}_{2}$ are decreasing, $\mathrm{NO}_{2}$ is stable, and all the other pollutants have decreasing concentrations throughout the whole period.

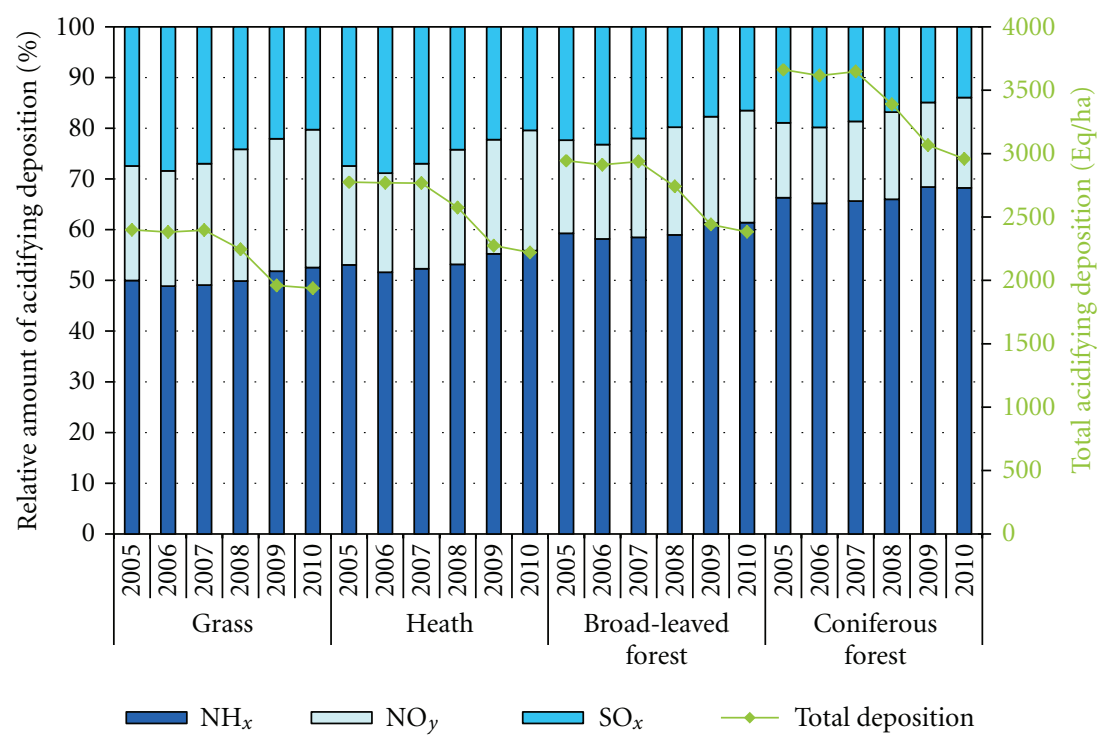

FIGURE 4: Overview of the total deposition from 2005 until 2010 for 4 different vegetation types and the relative amount for each pollutant. The relative amount for $\mathrm{NH}_{x}$ and $\mathrm{NO}_{y}$ increases, whereas the amount for $\mathrm{SO}_{x}$ decreases. Total deposition decreases throughout the 5 years.

The relative amount of acidifying deposition increases for $\mathrm{NH}_{3}(57 \%$ to $60 \%)$ and $\mathrm{NO}_{x}$ (19\% to $23 \%$ ). However Figure 3 shows that average concentrations in Flanders for $\mathrm{NH}_{3}$ are decreasing and for $\mathrm{NO}_{x}$ are staying stable. This can be explained by considering the sensitivity of the different vegetation types into the dry deposition measurements. For $\mathrm{SO}_{2}$, concentration measurements confirm a decrease from $24 \%$ to $18 \%$ in deposition (see Figures 3 and 4). Total acidifying deposition decreases throughout the 5 years, with a large decline from 2007 to 2009.

Additionally, the spread of acidifying deposition is also calculated with a mathematical model, called VLOPS (Vlaams Operationeel model voor Prioritaire Stoffen). This model calculates the concentrations 


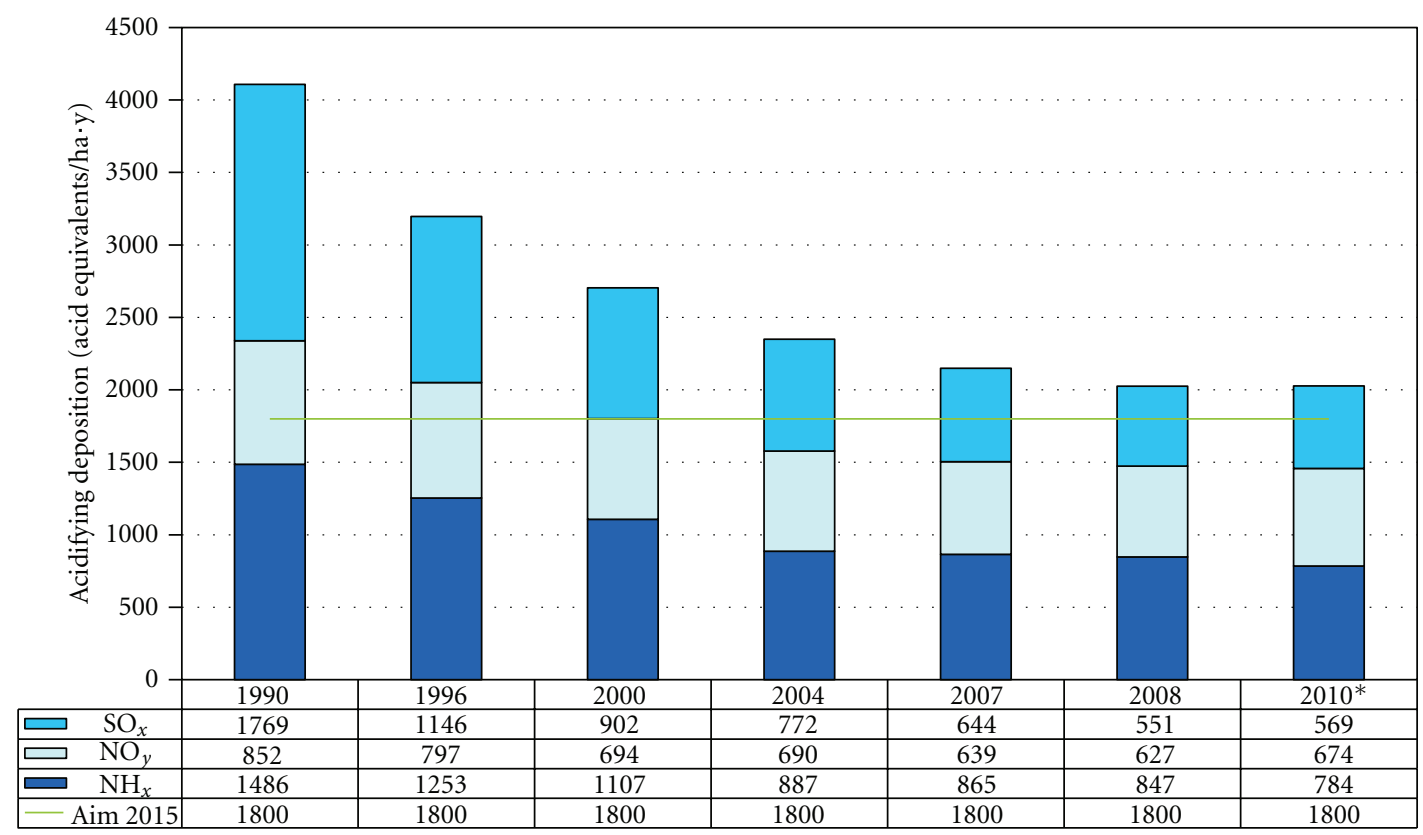

* Temporary figures

FIGURE 5: Average Flemish acidifying depositions of $\mathrm{SO}_{x}, \mathrm{NO}_{y}$, and $\mathrm{NH}_{x}$ from 1990 to 2010.

$\mathrm{SO}_{2}, \mathrm{NO}_{2}$, and $\mathrm{NH}_{3}$ and depositions $\mathrm{SO}_{x}, \mathrm{NO}_{y}$, and $\mathrm{NH}_{x}$ for Flanders on a $1 \times 1 \mathrm{~km}^{2}$ grid, using emissions estimates and meteorological statistics. Also information on the receptor area is taken into account [13]. In Figure 5 the average Flemish acidified deposition is calculated for 1990, 1996, 2000, 2004, 2007, 2008, and 2010. There is decreasing trend until 2008 after which little change is observed. The average total deposition in 2010 (2027 Eq/ha.y) is still higher than de Mina 4 (Flemish environmental policy plan) for 2015 (1800 Eq/ha.y) [14].

The pollutant $\mathrm{NH}_{3}$ is currently a hot topic. The widespread use of ammonia and its derivatives as agricultural nitrogen fertilizers has substantially increased emissions of ammonia to the atmosphere, leading to a wide range of different environmental problems. The current critical level for ammonia in Europe is set at $8 \mu \mathrm{g} / \mathrm{m}^{3}$ as an annual average concentration [13, 15]. As a result, there has been an evolution in the measurements of acid deposition, in the direction of increased measurements of ammonia in Flanders. Therefore, the VMM is intending to develop a strategy on ammonia measurements on a continuous basis. Our aim is to achieve policy-oriented measurements for general ammonia concentrations in Flanders. The development of this monitoring network on ammonia will include:

(i) a thorough literature research;

(ii) integration with other agencies and neighbouring countries;

(iii) improvement and validation of the model used;

(iv) to do market research on best available techniques for ammonia measurements;

(v) develop source or/and area-oriented measurements.

This development will be supported by sample analysis and statistical work.

It is also interesting to mention that VMM, together with some other experts, did research on the possibility of using lichens as a bioindicator to measure ammonia concentrations. The results from this research showed that these measurements may be a very interesting, for example, as a tool to measure the influence of ammonia on biodiversity in and around nature reserves. VMM wanted to develop a Flemish index, based on the monitoring of epiphytic lichens in Flanders. Through this index it was envisaged that 
locations in Flanders (or Belgium) with a yearly average ammonia concentration under the WHO standard

$\left(8 \mu \mathrm{g} / \mathrm{m}^{3}\right)$ could be distinguished from the locations in excess of this limit (published soon) [16].

\section{REFERENCES}

[1] Milieurapport Vlaanderen, Achtergronddocument Thema Ver-zuring, MIRA, VMM, 2006.

[2] VMM, "Lozingen in lucht, 1990-2009," Dienst Lucht, 2010.

[3] H. S. Lee, C. M. Kang, B. W. Kang, and H. K. Kim, "Seasonal variations of acidic air pollutants in Seoul, South Korea," At-mospheric Environment, vol. 33, no. 19, pp. 3143-3152, 1999.

[4] P. Elvingson and C. Ågren, Air and the Environment, Swedish Ngo Secretariat on Acid Rain, 2004.

[5] U. Dämmgen, J. W. Erisman, J. N. Cape, L. Grünhage, and D. Fowler, "Practical considerations for addressing uncertainties in monitoring bulk deposition," Environmental Pollution, vol. 134, no. 3, pp. 535-548, 2005.

[6] J. Staelens, A. De Schrijver, P. Van Avermaet, G. Genouw, and N. Verhoest, "A comparison of bulk and wet-only deposition at two adjacent sites in Melle (Belgium)," Atmospheric Environment, vol. 39, no. 1, pp. 7-15, 2005.

[7] H. Plaisance, S. Sauvage, P. Coddeville, and R. Guillermo, "A comparison of precipitation sensors used on the wet-only collectors," Environmental Monitoring and Assessment, vol. 51, no. 3, pp. 657-671, 1998.

[8] "Stageverslag juli 1999-juni 2000, Van Avermaet Philip, De-positie van verzurende componenten in Vlaanderen".

[9] J. Staelens, K. Wuyts, S. Adriaenssens et al., "Trends in atmospheric nitrogen and sulphur deposition in northern Belgium," Atmospheric Environment. In press.

[10] http://www.radiello.it/.

[11] http://www.diffusivesampling.ivl.se/.

[12] M. van Steertegem, Milieuverkenning 2030, Milieurapport Vlaanderen, VMM, 2009.

[13] M. A. Sutton, S. Reis, and S. M. H. Baker, Eds., Atmospheric Ammonia-Detecting Emission Changes and Environmental Impacts, Springer, Berlin, Germany, 2009.

[14] VMM, 'Zure Regen' in Vlaanderen, Depositiemeetnet Verzuring, 2009.

[15] M. R. Ashmore and R. B. Wilson, Eds., Critical Levels of Air Pollutants for Europe, Departement of the Environment, London, UK, 1994.

[16] D. Van den Broeck, M. Herremans, G. Verbeylen, L. Jacobs, and Dorsselaer P. Van, "Korstmossen als indicator voor ammoniakconcentraties (Eindrapport)," Tech. Rep. number 2009/2, Natuurpunt Studie, Mechelen, Belgium, 2009.

\section{This article should be cited as follows:}

Bo Van den Bril, Dominique Meremans, and Edward Roekens, "A Monitoring Network on Acidification in Flanders, Belgium,” TheScientificWorldJOURNAL, vol. 11, pp. 2358-2363, 2011. 

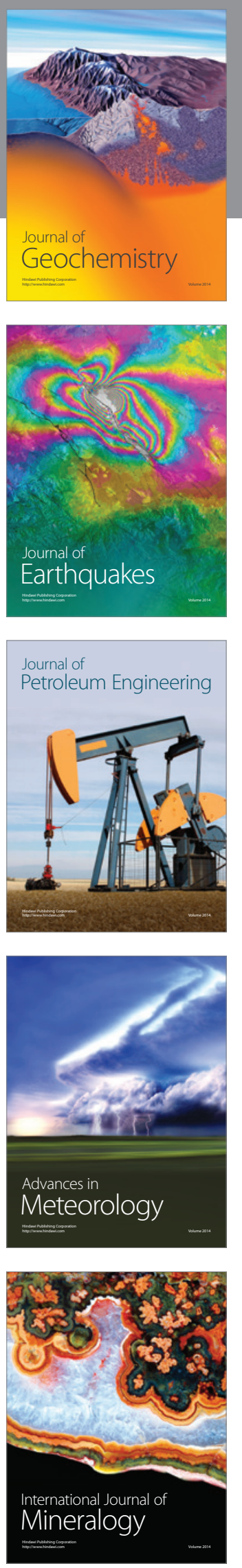
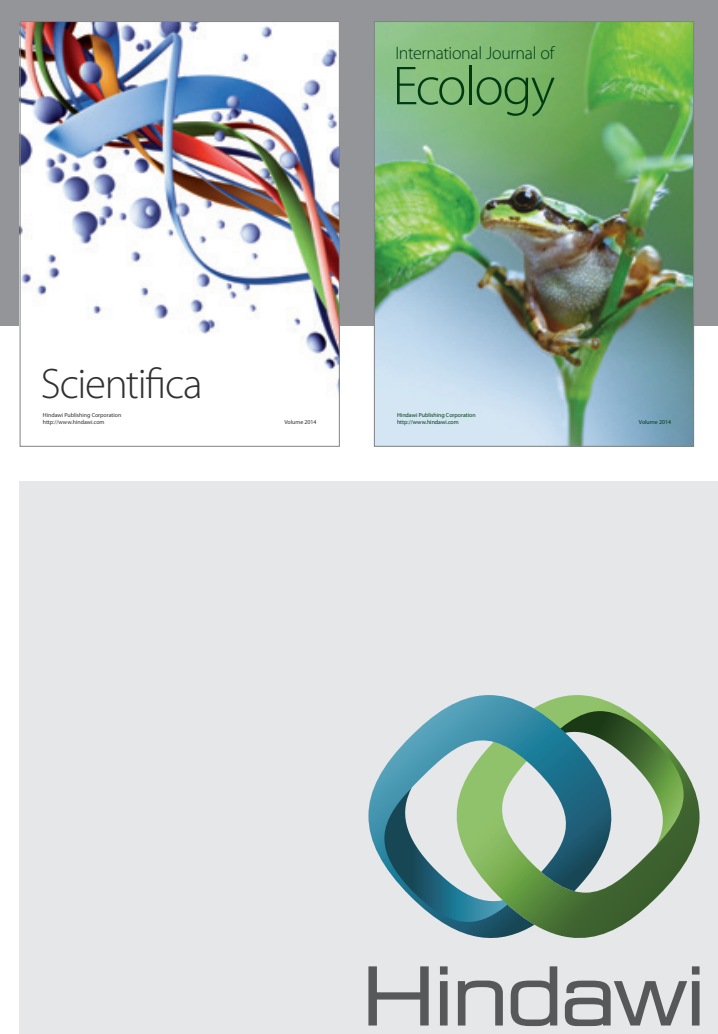

Submit your manuscripts at http://www.hindawi.com
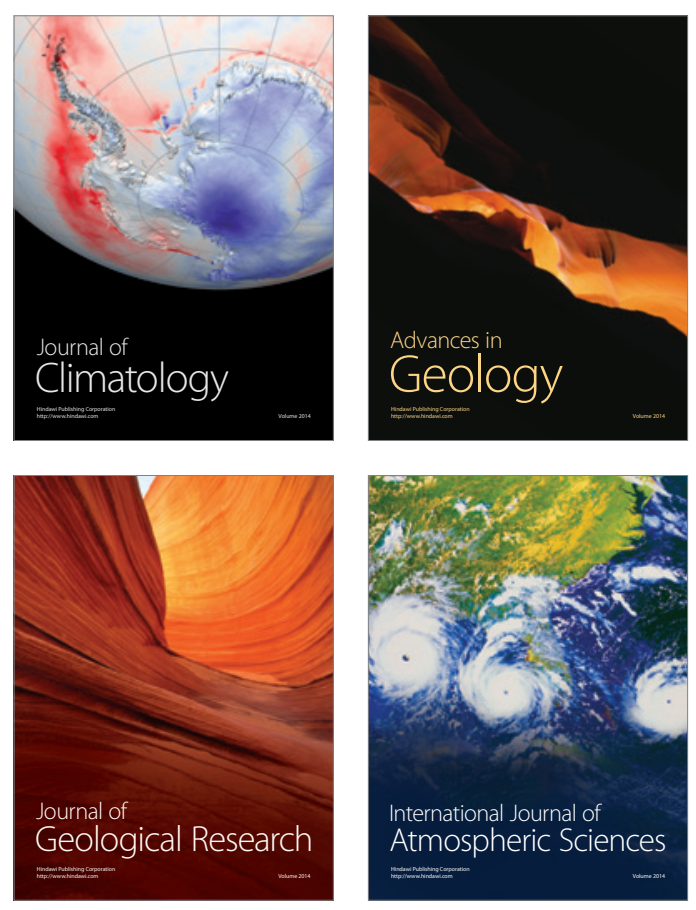
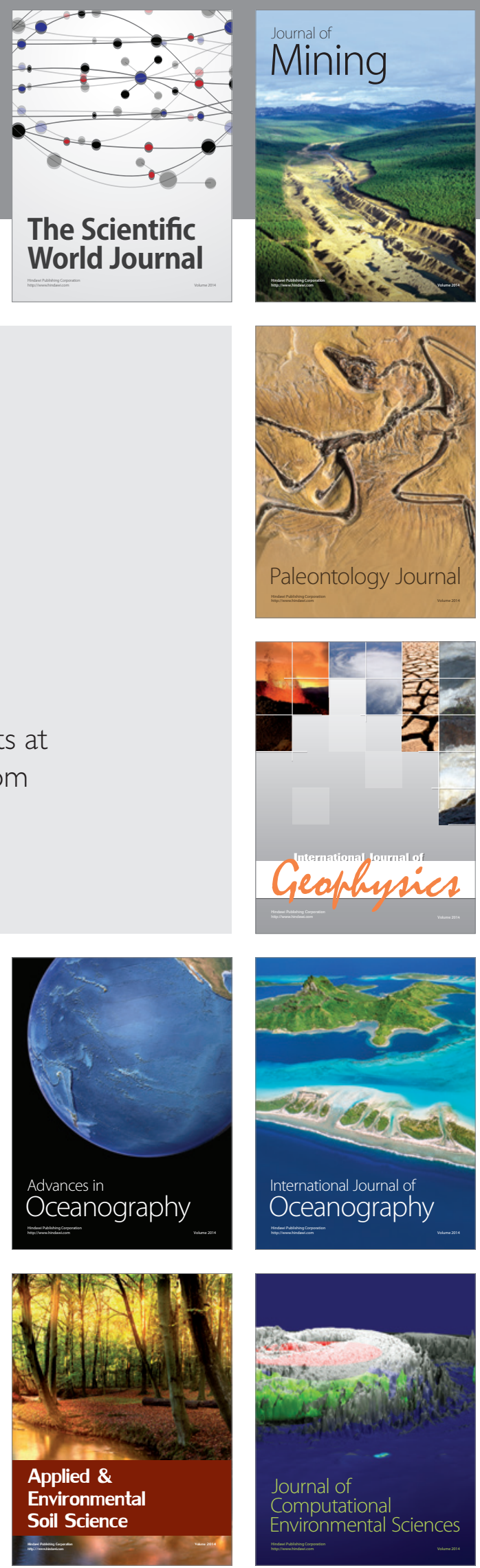